\title{
Vulval and Vaginal Haematomata
}

\author{
J. H. SCUDAMORE,* M.B., CH.B., M.R.C.o.G.
}

Brit. med. F., 1964, 1, 1357-1358

In obstetric practice haemorrhage continues to be the second greatest cause of maternal death. This paper draws attention to a particularly elusive and therefore dangerous type of haemorrhage which takes place with the formation of pelvic haematomata.

\section{Case Reports}

Case 1.-Mrs. A, a 29-year-old multipara, was delivered normally at term. No episiotomy had been made nor was there any perineal tear. A haematoma of the left labium developed soon after delivery and the obstetric flying squad was called. A large haematoma was found beginning to break through the skin. A blood transfusion was set up and the patient transferred to hospital. Under general anaesthesia the haematoma was evacuated, haemostasis secured; and the cavity obliterated with catgut sutures. The vagina was packed and the bladder drained with a self-retaining catheter. Penicillin and sulphadimidine were given. The postoperative course was uneventful. Her ante-partum haemoglobin was $69 \%$, and although she was given 6 bottles $(3,240 \mathrm{ml}$.) of blood the level was only $63 \%$ on discharge from hospital.

Case 2.-Miss B, a primigravida, had a normal labour and an uneventful delivery, save that a small left postero-lateral episiotomy was performed. Before this could be repaired a haematoma of the left labium began to form, causing intense pain. A -transvaginal pudendal block was introduced; this relieved the pain immediately, allowing the haematoma to be evacuated through the episiotomy wound. Haemostasis was secured and the cavity obliterated with catgut sutures. The episiotomy was repaired in the usual way. The puerperium was normal and the wound healed well.

Case 3.-Mrs. C, a primigravida aged 35, was delivered with forceps under pudendal-block anaesthesia. An episiotomy was repaired with catgut. Two hours later she complained of pain in the back, but there was no sign of any abnormality in the perineal region. Four and a half hours after delivery a small swelling was noted in the region of the episiotomy and right labium; this increased in size rapidly and obviously required active treatment (see Fig.). The pain was now very severe but the patient's general condition remained good. The haematoma was evacuated and was found to extend into the right ischio-rectal fossa. The cavity and vagina were packed, and a self-retaining catheter was introduced into the bladder. At least $20 \mathrm{oz}$. $(570 \mathrm{ml}$.) of blood and clot was lost. Although this was replaced by the transfusion of $540 \mathrm{ml}$. of blood, the amount was obviously insufficient, as her haemoglobin fell from $91 \%$ to $56 \%$. The pack was removed after 24 hours. The tissues then fell together, and subsequent healing was good.

Case 4.-Mrs. D, a primigravida, had a low-forceps delivery of a $7 \mathrm{lb} .6 \mathrm{oz} .(3,345 \mathrm{~g}$.) baby at term. A postero-lateral episiotomy was made and was repaired with a continuous catgut stitch. After completing the repair a finger was introduced into the vagina to make sure that the suture line was firm. A tense swelling filling the upper vagina was felt in the posterior vaginal wall at the upper level of the suture line. The episiotomy was broken down and blood was released from the haematoma cavity. Fresh bleeding continued, so, without waiting for a general anaesthetic to be administered, a gauze pack was inserted firmly into the cavity. This temporarily controlled the bleeding. An intravenous infusion of saline was set up, blood was cross-matched and the patient anaesthetized. The haematoma cavity was explored and a bleeding-point, deep to the posterior vaginal wall at a high level, was grasped with sponge forceps and underpinned with catgut. As the tissues were friable the large cavity was packed with sterile gauze and a selfretaining catheter inserted into the bladder. During the operation

* Nuffield Department of Obstetrics and Gynaecology, University of Oxford. the blood-pressure fell from $120 / 70$ to $60 / 30$, but after one bottle $(540 \mathrm{ml}$.) of saline and two bottles $(1,080 \mathrm{ml}$.) of blood the general condition was satisfactory. The pack and catheter were removed after 48 hours and the episiotomy was then resutured. The patient was given penicillin and sulphadimidine for five days. Her subsequent convalescence was uneventful ; the perineum and paravaginal tissues healed well.

Case 5.-Mrs. B, a para-1 aged 26, had a normal delivery of a baby weighing $9 \mathrm{lb} .6 \mathrm{oz}$. (4,250 g.). There was no injury to the perineum. One hour after delivery she complained of pain in the perineum and left leg. The pain worsened and she became restless and distressed. The blood-pressure was $135 / 80$ and the pulse 80 . Movement of the left hip aggravated her pain. There was no evidence of a vulval haematoma, but vaginal examination

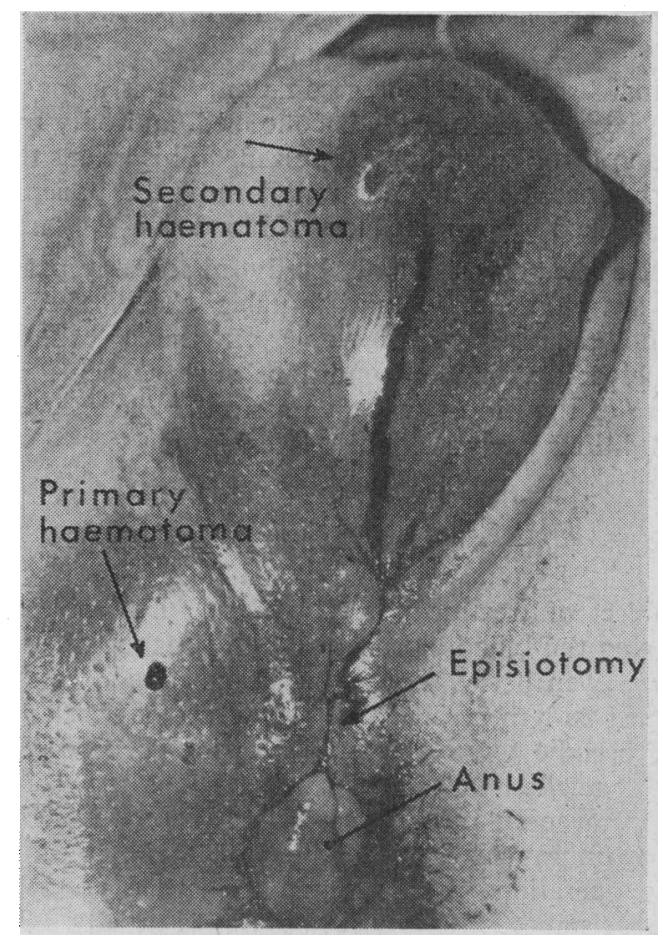

Right labial haematoma. Case 3.

showed a tender swelling arising on the left side and occluding the vaginal canal. Under general anaesthesia the swelling was opened through the lateral vaginal wall and found to be a large haematoma. After evacuating the clot a bleeding vessel was found at a high level and was underpinned with a figure-of-8 catgut suture. The cavity and vagina were packed with sterile gauze, which was removed 24 hours later. The patient was given two bottles $(1,080 \mathrm{ml}$.$) of blood and put on a course of penicillin and sulpha-$ dimidine. After the operation her pain was completely relieved, and although she had some discomfort on walking this disappeared after two weeks. The vagina healed well without any further treatment.

\section{Incidence and Aetiology}

There is a wide discrepancy in the reported incidence. of pelvic haematomata varying from $1: 300$ to $1: 5,474$ deliveries. Sotto and Collins (1958) reported 47 cases in 14,548 confine- 
ments ; in each case there had been some form of perineal trauma. Their criterion regarding the size of the tumour for inclusion in their report was a measurement of at least $1 \frac{1}{2}$ in. $(3.8 \mathrm{~cm}$.) in diameter.

Many factors have been suggested as a cause of haematomata, yet healthy mothers sometimes are affected after an apparently normal confinement. There is obviously no simple explanation for the condition.

Pieri (1958) has described the anatomical relations very clearly. Should a vessel in the tissues superficial to the triangular ligament bleed, then the haematoma will be confined to the subcutaneous tissues and will appear as a vulval haematoma. Deep to the triangular ligament, bleeding will be confined by the superior levator fascia and extension will take place in an upward direction without any outward sign of haematoma formation. At a higher level subperitoneal haematomata may form, giving rise to great diagnostic difficulties (Macafee and Magee, 1956).

\section{Diagnosis}

Should a vessel in the superficial tissues bleed, sooner or later a tense purple swelling begins to distend the vulva and surrounding perineum. These signs are preceded by severe cutting pain, and if the perineal region is inspected the diagnosis is obvious.

A vaginal haematoma is less common. It is a more serious condition because the tumour is concealed, and only by vaginal examination is the condition recognized. This means that many of these haematomata are not found until the patient is profoundly shocked by pain and loss of blood.

Because a haematoma may be easily missed, any patient with unusual symptoms and unaccountable shock after delivery snould be examined vaginally, even though there is no external bleeding. Other conditions such as acute inversion or rupture of the uterus will give a similar picture, and in all these conditions early diagnosis is essential.

\section{Management}

The object of treatment is to prevent further bleeding and by removing the blood clot to lessen the chance of subsequent infection. Even if the general condition is good before operation it must be remembered that the degree of shock and blood loss may become severe during the operative procedure. For all but the smallest vulval haematomata it is therefore wise to have an intravenous infusion set up and blood available before embarking on any surgical operation for this condition. As in all pelvic operations it is essential to have a good light and adequate assistance. General anaesthesia is usually necessary.

The haematoma should first be evacuated and an attempt made to locate the bleeding vessel. If possible this should be tied off and the dead space obliterated with interrupted catgut sutures. This is not easy, as the tissues are very friable and ordinary haemostatic forceps of the Spencer Wells variety will cut through the friable tissues. Stiles's tissue forceps or sponge-holding forceps are more satisfactory for grasping bleeding-points, which can be underpinned with figure-of- 8 catgut sutures.

Vaginal haematomata are less easily accessible and it is often impossible to find the bleeding vessel, which may have retracted to a high level. In these cases the haematoma should be evacuated and the cavity and vagina packed firmly with sterile gauze. When the pack is removed, the tissues fall together remarkably quickly and the normal anatomy is soon reestablished. It is unnecessary to carry out secondary suture of the tissues, however distorted the anatomy appears when the packing is first removed.

In all the cases reported, replacement of blood was insufficient in amount (see Table). Estimation of blood lost is notoriously difficult and is more often underestimated than overestimated. There is no easy way to decide how much blood it is necessary to give, but if the transfusion is sufficient the post-operative course is less likely to be complicated.

\begin{tabular}{c|c|c|c}
\multicolumn{5}{c}{ Summary of Cases } \\
\hline \begin{tabular}{c|c} 
Case \\
No.
\end{tabular} & $\begin{array}{c}\text { Ante-partum } \\
\text { Haemoglobin }\end{array}$ & $\begin{array}{c}\text { Amount of } \\
\text { Blood Given }\end{array}$ & $\begin{array}{c}\text { Post-partum } \\
\text { Haemoglobin }\end{array}$ \\
\hline 1 & $69 \%$ & 6 bottles $(3,240 \mathrm{ml})$. & $63 \%$ \\
2 & $88 \%$ & None & $64 \%$ \\
3 & $91 \%$ & 1 bottle $(540 \mathrm{ml})$. & $56 \%$ \\
4 & $66 \%$ & 2 bottles $(1,080 \mathrm{ml})$ & $60 \%$ \\
5 & $88 \%$ & 2 bottles $(1,080 \mathrm{ml})$. & $68 \%$ \\
\hline
\end{tabular}

$100 \%$ haemoglobin $=14 \cdot 8 \mathrm{~g} \cdot / 100 \mathrm{ml}$.

\section{Summary}

After any vaginal delivery a pelvic haematoma may form. If the condition is missed there may be serious consequences.

Even if the general condition of the patient is good before surgical treatment is begun, some degree of shock becomes apparent during the procedure. For this reason it is much better to have an intravenous infusion running and blood available before treatment is begun rather than have to interrupt surgery in order to resuscitate the patient.

It is most unwise to attempt to deal with a pelvic haematoma in a patient's home and without adequate facilities. A good anaesthetic, available blood, a good light, adequate assistance to expose the haematoma cavity, and the proper instruments are essential.

In all the cases reported, replacement of blood was insufficient in amount (see Table). Estimation of blood lost is notoriously difficult and more often underestimated than overestimated.

\section{REFERENCES}

Macafee, C. H. G., and Magee, R. A. E. (1956). F. Obstet. Gynaec. Brit. Emp., 63, 349.

Pieri, R. J. (1958). Obstet. and Gynec., 12, 249.

Sotto, L. S. J., and Collins, R. J. (1958). Ibid., 12, 259. 